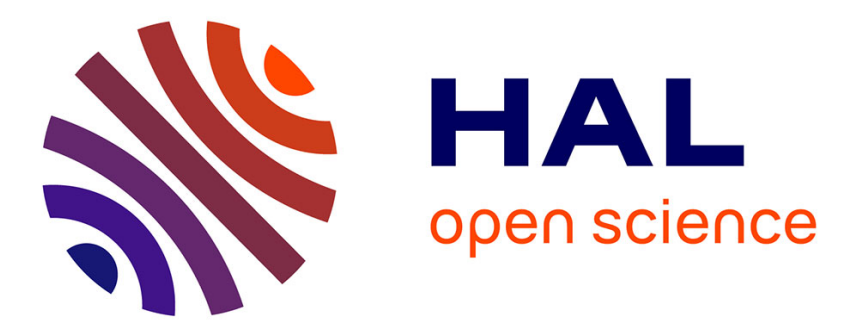

\title{
Depth-resolved analysis of spontaneous phase separation in the growth of lattice-matched AlInN
}

A Redondo-Cubero, K Lorenz, R Gago, N Franco, M.-A Di Forte Poisson, E Alves, E Muñoz

\section{- To cite this version:}

A Redondo-Cubero, K Lorenz, R Gago, N Franco, M.-A Di Forte Poisson, et al.. Depth-resolved analysis of spontaneous phase separation in the growth of lattice-matched AlInN. Journal of Physics D: Applied Physics, 2010, 43 (5), pp.55406. 10.1088/0022-3727/43/5/055406 . hal-00569755

\section{HAL Id: hal-00569755 \\ https://hal.science/hal-00569755}

Submitted on 25 Feb 2011

HAL is a multi-disciplinary open access archive for the deposit and dissemination of scientific research documents, whether they are published or not. The documents may come from teaching and research institutions in France or abroad, or from public or private research centers.
L'archive ouverte pluridisciplinaire HAL, est destinée au dépôt et à la diffusion de documents scientifiques de niveau recherche, publiés ou non, émanant des établissements d'enseignement et de recherche français ou étrangers, des laboratoires publics ou privés. 


\title{
Depth-resolved analysis of spontaneous phase separation in the growth of lattice-matched AlInN
}

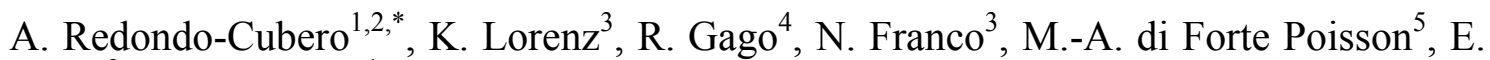 \\ Alves $^{3}$ and E. Muñoz ${ }^{1}$ \\ ISOM and Dpt. de Ingeniería Electrónica, ETSI Telecomunicación, Universidad Politécnica de \\ Madrid, E-28040 Madrid, Spain. \\ 2 Centro de Micro-Análisis de Materiales, Universidad Autónoma de Madrid, E-28049 Madrid, Spain. \\ 3 Instituto Tecnológico e Nuclear, Estrada nacional 10, 2686-953 Sacavém, Portugal. \\ 4 Instituto de Ciencia de Materiales de Madrid (CSIC), E-28049 Madrid, Spain. \\ 5 Thales Research \& Technology/TIGER, 91461 Marcoussis Cedex, France.
}

\section{ABSTRACT:}

We report the detection of phase separation of an $\mathrm{Al}_{1-\mathrm{x}} \mathrm{In}_{\mathrm{x}} \mathrm{N} / \mathrm{GaN}$ heterojunction grown close to lattice matched conditions $(x \sim 0.18)$ by means of Rutherford backscattering spectrometry in channeling geometry and high resolution x-ray diffraction. An initial pseudomorphic growth of the film was found, with good single crystalline quality, the nominal composition and very low strain state. After $\sim 50 \mathrm{~nm}$, a critical thickness is reached at which the $\mathrm{InN}$ molar fraction of the films drops to $\sim 15 \%$ and at the same time the single crystalline quality of the films degrade drastically. This spontaneous effect cannot be ascribed to strain relaxation mechanisms since both techniques show a good single crystalline growth of the ternary under lattice matched conditions.

Keywords: RBS, channeling, AlInN, strain, XRD

* Corresponding author: andres.redondo@uam.es 


\section{INTRODUCTION}

The epitaxial growth of high quality heterostructures (HS) is one fundamental issue for the development of semiconductor devices. This fact is particularly important in the case of III-nitrides because of the lack of good substrates to grow them and the large lattice mismatch between $\mathrm{GaN}$ and the typical ternaries used in most nitride devices (InGaN and AlGaN). [1]. Even so, GaN-based devices have good performance in highpower optoelectronic and microelectronic applications (light emission diodes, high electron mobility transistors, Bragg reflectors, etc.) [2-4]. The bandgap of the IIInitrides can be varied with the composition covering a very extensive optical range, from $0.6 \mathrm{eV}(\mathrm{InN})$ to the $6 \mathrm{eV}(\mathrm{AlN})$ region, which is one of the main advantages of these systems [5].

Ternary $\left(\mathrm{Al}_{1-\mathrm{x}} \mathrm{In}_{\mathrm{x}} \mathrm{N}\right)$ and quaternary $\left(\mathrm{Al}_{\mathrm{y}} \mathrm{Ga}_{1-\mathrm{x}-\mathrm{y}} \mathrm{In}_{\mathrm{x}} \mathrm{N}\right)$ nitrides are the best candidates to reduce the negative effect of lattice mismatch in HS since they actually can be grown in lattice-matched conditions to GaN. In the case of AlInN this lattice-matched conditions correspond to a composition with $\sim 18 \%$ of InN content while the quaternary alloys have more degrees of freedom and the band gap energy can be tuned between that of $\mathrm{GaN}(3.4 \mathrm{eV})$ and that of $\mathrm{Al}_{0.82} \mathrm{In}_{0.18} \mathrm{~N}(4.4 \mathrm{eV})[6]$. Nevertheless, due to the inherent differences between the binaries ( $\mathrm{AlN}, \mathrm{InN})$ associated with lattice parameters, bonding energies and growth temperatures [7], some remaining problems can still restrict the capabilities of these systems. In particular, phase separation $[6,8-10]$, InN segregation $[11,12]$, relaxation processes [13] and deviations from Vegard's law [14-17] have been already identified experimentally and theoretically in these HS. Phase separation is, in fact, one of the proved mechanisms related with the enhanced luminescence in AlInGaN epilayers [18, 19]. 
These deviations may occur as a function of the thickness, the growth rate, the temperature, etc. Therefore, an accurate depth-resolved characterization of this kind of HS is crucial for the correct optimization of the growth parameters and the understanding of the underlying physical phenomena taking place during this process. High-resolution x-ray diffraction (HR-XRD) is a common and powerful tool for the analysis of lattice parameters and composition of III-nitrides [20]. However, in general it does not provide depth resolution and, in lattice-matched HS, the overlapping peaks from film and substrate can reduce the accuracy of the measurement affecting the correct determination of the composition. In the case of the quaternaries, this compositional analysis by XRD cannot be carried out because of the lack of sufficient parameters.

As an alternative, Rutherford backscattering spectrometry (RBS) is a well established technique for the determination of the compositional profile of thin films with a depth resolution of some nanometres [21]. This is a non-destructive method providing the elemental concentration several microns inside the material, and it has been successfully used in III-nitrides systems [22]. Furthermore, for heavy elements such as In and Ga, the sensitivity is very high due to the elevated backscattering cross-section, making possible the detection of changes of less than $1 \%$ at.

An additional advantage of this technique is the useful structural information it can provide when combined with ion channeling phenomena (RBS/C) [23]. This situation takes place when the beam is aligned with a major symmetry direction of the crystal producing an intense reduction of the backscattering events in the spectrum. The ratio between aligned and random yields is called minimum yield $\left(\chi_{\min }\right)$ and can be used as an indicator of the crystalline quality of the film in RBS/C. Angular scans along the 
crystallographic axes show a characteristic dip that contains further structural details. In particular, the strain state of the film can be quantified using the incidence along an oblique axis as shown in Fig. 1. Since the film and the substrate have, in principle, different lattice parameters, the minima of the dips will occur at different angles. The difference between them is known as kink angle, $\Delta \theta=\theta^{\text {subs }}-\theta^{\text {fim }}$, and it can be correlated with the strain state.

We report here the detection of phase separation in an AlInN/GaN HS by RBS/C. A random configuration was used for the determination of the compositional profile, whereas the $<0001>$ aligned spectrum was employed to correlate the composition with the structural differences in the film. Both properties proved to be closely linked. Further analysis with angular scans along the $<\overline{2} 113>$ axis was performed to find the strain state of the film. The obtained value was contrasted with HR-XRD.

\section{EXPERIMETAL}

The studied AlInN/GaN HS was grown on (0001) sapphire by low-pressure chemical vapour deposition (LP-CVD) in an Aixtron 200RF reactor. Gas precursors were trimethyl-Al, trimethyl-In and ammonia $\left(\mathrm{NH}_{3}\right)$, using 50 mbar of pressure. The growth rate was $2 \mathrm{~nm} / \mathrm{min}$. The $110 \mathrm{~nm}$ thin layer of $\mathrm{AlInN}$ was deposited at $860{ }^{\circ} \mathrm{C}$, with a V/III ratio of 2700 .

RBS/C experiments were performed with a $1.5 \mathrm{MeV}{ }^{4} \mathrm{He}^{+}$beam, $1 \mathrm{~mm}^{2}$ of size. Backscattered ions were detected simultaneously by two silicon barrier detectors (energy resolution of $16 \mathrm{keV}$ ) placed at $125^{\circ}$ and $170^{\circ}$ in IBM geometry. A 3-axes goniometer was employed to control the crystal position with an accuracy of $0.01^{\circ}$. Angular scans across $<0001>$ and $<\overline{2} 113>$ axes were recorded in steps of $0.05^{\circ}$ to 
determine the crystallinity grade and the strain state of the film. Random spectra up to a dose of $5 \mu \mathrm{C}$ were acquired by rotating the sample during the measurement. Both aligned and random spectra were simulated using the RBX code [24].

Reciprocal space maps (RSMs) of the AlInN/GaN HS were acquired in a D8Discover high resolution diffractometer (Bruker-AXS) using $\mathrm{Cu}\left(\mathrm{K}_{\alpha 1}\right)$ radiation, an asymmetric two-bounce $\mathrm{Ge}(220)$ monochromator, and a scintillation $\mathrm{NaI}(\mathrm{Tl})$ detector. The in-plane (a) and out-of-plane (c) lattice parameters were extracted from RSMs around the (0004) and $(10 \overline{15})$ reflections.

\section{RESULTS AND DISCUSSION}

Random and $<0001>$ aligned spectra of the $\mathrm{Al}_{1-\mathrm{x}} \mathrm{In}_{\mathrm{x}} \mathrm{N} / \mathrm{GaN}$ HS from RBS/C experiments are shown in Figure 2. The elemental concentration was determined by means of the RBX simulation, also exposed in the graph. The In signal (1200-1375 keV) is completely separated from the Ga substrate signal in the spectrum, what gives an accurate measurement of the concentration. On the contrary, the Al signal (800-1000 $\mathrm{keV}$ ) is overlapped with the $\mathrm{Ga}$ one due to the lighter mass. However, since the $\mathrm{Al}$ concentration is high, the signal is clearly distinguishable in the spectrum. For the fitting, a two-layer model had to be used, corresponding to two different energy windows ( $\mathrm{w}_{1}$ and $\mathrm{w}_{2}$ in the figure). Figure 3 shows the extracted profile in detail. On one hand, $\mathrm{w}_{1}$ (surface, $\sim 60 \mathrm{~nm}$ ) shows a flat signal fitted with a single layer of $x=0.15$. On the other, $\mathrm{w}_{2}$ (interface, $\sim 50 \mathrm{~nm}$ ) exhibits a higher backscattering yield fitted with a composition of $x=0.18$. Thus, two different compositions were accomplished during the growth. 
The aligned spectrum along the $<0001>$ axis reveals that both compositional regions show also different structural behaviours. The yield in $\mathrm{w}_{1}$ is the same as in the random spectrum $\left(\chi_{\min }=100 \%\right)$, what indicates that this part of the film is composed of an amorphous or polycrystalline material. However, the yield in $\mathrm{w}_{2}$ is clearly reduced by the channeling effect $\left(\chi_{\min }=62 \%\right)$, even after the dechanneling induced by the first layer, which indicates that the interface layer is single-crystalline. Thus, the change in the composition is accompanied by a strong deterioration of crystal quality, confirming the existence of two different phases in the AlInN film.

This fact was verified in three additional samples grown under similar conditions but with different thicknesses (up to $\sim 200 \mathrm{~nm}$ ). The thickness of the first In-rich layer $\left(\mathrm{w}_{2}\right)$, however, was in the same range for all of the samples $(\sim 50 \mathrm{~nm})$, indicating the existence of a critical thickness for the growth. This suggests that the phase separation is occurring spontaneously during the growth. The occurrence of such compositional gradients has been detected previously for different AlInN films [13, 14]. Nevertheless, in these cases the deterioration of the crystal quality was explained by strain relaxation effects which cannot be the cause in our lattice-matched films. Despite AlInN films close to lattice-matched conditions normally present a pseudomorphic growth [14], the compositional gradient in our samples is leading away from the lattice-matched composition, so the expected behaviour is not coherent with a relaxation process during the growth as in other samples [13].

In order to verify this point, the strain state of the crystalline AlInN phase $\left(\mathrm{w}_{2}\right)$ was measured by angular scans along the $<0001>$ and $<\overline{2} 113>$ axes. Figure 4 shows both scans for the In $\left(\mathrm{w}_{2}\right)$ and the Ga signal $\left(\mathrm{w}_{3}\right)$. The minimum in the $<0001>$ scan is reached in the same position, since this axis is not sensitive to the tetragonal distortion. 
However, the $<\overline{2} 113>$ axis is located at $\theta \sim 31.6^{\circ}$ along the (10 $\left.\overline{1} 0\right)$ plane and verifying $\tan \theta=a / c$. Then, the angular scan in this axis is sensitive to the different lattice parameters in film and substrate. The observed shift in the positions of both dips is related to the different $a / c$ ratio of both AlInN film and GaN substrate (see Figure 1). The experimental kink angle was calculated from the minima, finding a value of $\Delta \theta=-$ $0.36(2)^{\circ}$. Following Vegard's law and assuming the RBS mean composition, the theoretical $\Delta \theta$ for a relaxed AlInN layer would be $-0.363^{\circ}$. As expected for a film with $x=0.18$, it can be concluded that the first part of the AlInN film was grown directly relaxed within the experimental errors of $\mathrm{RBS} / \mathrm{C}$.

RSMs of the AlInN/GaN heterostructure for the (0004) and (1015) planes are shown in Figure 5. The (0004) map reveals that there are no macroscopic tilts between the film and GaN substrate. Lattice parameters of both layers were extracted from the (10 $\overline{15})$ map, since $Q_{x}$ and $Q_{z}$ are inversely proportional to $a$ and $c$, respectively. Values for the GaN layer was found to be $a=3.188(1) \AA, c=5.188(1) \AA$, while AlInN film showed $a=3.190(1) \AA, c=5.111(1) \AA$. The composition value extracted from these lattice parameters considering biaxial strain and using Vegard's law is $x=0.183$, in excellent agreement with the RBS results. No XRD signal from the surface layer $\left(\mathrm{w}_{1}\right)$ was found at the expected positions for strained or relaxed AlInN with $x \sim 0.15$. The absence of such a crystalline phase in the RSM, however, can be easily explained by the lack of crystalline quality in this layer.

Following the experimental data, parallel and perpendicular strain of the AlInN layer were calculated as $\varepsilon^{\|}=\left(a-a_{0}\right) / a_{0}$ and $\varepsilon^{\perp}=\left(c-c_{0}\right) / c_{0}$. The $a_{0}$ and $c_{0}$ parameters represent values for a relaxed AlInN film taking into account the Vegard's law [25]. 
Since RBS/C experiments demonstrated that only the initial layer of $\mathrm{Al}_{0.82} \mathrm{In}_{0.18} \mathrm{~N}$ shows a crystalline behaviour, we use this composition in the calculation of the relaxed parameters. Thus, it was obtained $\varepsilon^{\|}=0.02(3) \%$ and $\varepsilon^{\perp}=-0.03(2) \%$. The resulting tetragonal distortion $\left(\varepsilon_{T}=\varepsilon^{\|}-\varepsilon^{\perp}\right)$ was $0.05(5) \%$. The very low parallel strain indicates the lattice matched growth achieved in the first step of the growth. The value of tetragonal distortion is almost zero (relaxed), which is in good agreement with the $\mathrm{RBS} / \mathrm{C}$ results.

On the basis of these results, the spontaneous degradation of the crystal quality together with the compositional grading cannot be attributed to mechanical stresses during the growth of the ternary film, but to other thermodynamic or chemical effects influencing the atomic ordering. Indeed, the important role of the temperature and the $\operatorname{InN}$ decomposition in the growth regime of AlInN epilayers has been recently confirmed [6, 7]. Consequently, oscillations of the temperature during the growth can provoke the formation of In droplets, changing the effective incorporation of In to the lattice and breaking the local-order of the nitride. The existence of such phase separation due to the different affinity of In-In bonds with temperature has been already demonstrated theoretically [9].

\section{CONCLUSIONS}

In this study, RBS/C and HR-XRD experiments on AlInN/GaN heterostructures were reported. Different compositional and structural phases were identified in the RBS/C analysis, being both of them related. Only the first $50 \mathrm{~nm}$ of the AlInN film shows pseudomorphic single crystalline growth, corresponding with lattice matched conditions $(x=0.18)$. Analysis of the RBS/C angular scans as well as HR-XRD RSMs revealed an 
almost relaxed interfacial layer. However, after the growth of $\sim 50 \mathrm{~nm}$, the film shows a drastic degradation of the crystal quality and a decrease of the InN content as observed by $\mathrm{RBS} / \mathrm{C}$.

\section{ACKNOWLEDGMENTS}

We acknowledge financial support by EU-FP6 (MOU 04/102.052/032), the Spanish MEC (FIS2009-12964-C05-04), FCT, Portugal (PTDC/FIS/66262/2006). Authors also thank fruitful discussions with S. Fernández-Garrido and F. González-Posada. 
References:

[1] L. Liu, and J.H. Edgar, Mater. Sci. Eng. R 37, 61 (2002).

[2] S. Nakamura, M. Senoh, and T. Mukai, Appl .Phys. Lett. 62, 2390 (1993).

[3] S. Nakamura, M. Senoh, S. Nagahama, N. Iwasa, T. Yamada, T. Matsushita, Y. Sugimoto and H. Kiyoku, Appl. Phys. Lett. 69, 4056 (1996).

[4] M. Gonschorek, J.-F. Carlin, E. Feltin, M. A. Py and N. Grandjean, Appl .Phys. Lett. 89, 062106 (2006).

[5] J. Wu, J. Appl. Phys. 106, 011101 (2009).

[6] R. Butté, J-F. Carlin, E. Feltin, M. Gonschorek, S. Nicolay, G. Christmann, D. Simeonov, A. Castiglia, J. Dorsaz, H. J. Buehlmann, S. Christopoulos, G .Baldassarri Höger von Högersthal, A. J. D. Grundy, M. Mosca, C. Pinquier, M. A. Py, F. Demangeot, J. Frandon, P. G. Lagoudakis, J. J. Baumberg and N. Grandjean, J. Phys. D: Appl. Phys. 40, 6328 (2007).

[7] S. Fernández-Garrido, Ž. Gačević and E. Calleja, Appl .Phys. Lett. 93, 191907 (2008).

[8] C. Hums, J. Bläsing, A. Dadgar, A. Diez, T. Hempel, J. Christen, A. Krost, K. Lorenz and E. Alves, Appl .Phys. Lett. 90, 022105 (2007).

[9] M. Marques, L. K. Teles, L. M. R. Scolfaro, L. G. Ferreira and J. R. Leite, Phys. Rev. B 70, 073202 (2004).

[10] T. Matsuoka, Appl .Phys. Lett. 71, 105 (1997).

[11] E. Monroy, D. Gogneau, D. Jalabert, E. Bellet-Amalric, Y. Hori, F. Enjalbert, L. S. Dang and B. Daudin, Appl .Phys. Lett. 82, 2242 (2003). 
[12] S. Fernández-Garrido, A. Redondo-Cubero, R. Gago, F. Bertram, J. Christen, E. Luna, A. Trampert, J. Pereiro, E. Muñoz and E. Calleja, J. Appl. Phys. 104, 083510 (2008).

[13] K. Lorenz, N. Franco, E. Alves, S. Pereira, I.M. Watson, R.W. Martin, K.P. O’Donnell, J. Cryst. Growth 310, 4058 (2008).

[14] V. Darakchieva, M. Beckers,M.-Y. Xie, L. Hultman, B. Monemar, J.-F. Carlin, E. Feltin, M. Gonschorek and N. Grandjean, J. Appl. Phys. 103, 103513 (2008).

[15] T. Seppänen, L. Hultman, J. Birch, M. Beckers and U. Kreissig, J. Appl. Phys. 101, 043519 (2007).

[16] K. Lorenz, N. Franco, E. Alves, I.M. Watson, R.W. Martin and K.P. O’Donnell, Phys. Rev. Lett. 97, 85501 (2006).

[17] B.-T. Liou, S.-H. Yen and Y.-K. Kuo, Appl. Phys. A 81, 651 (2005).

[18] C. H. Chen, Y.F. Chen, Z.H. Lan, L.C. Chen, K.H. Chen, H.X. Jiang and J.Y. Lin, Appl. Phys. Lett. 84, 1480 (2004).

[19] H. Hirayama, A. Kinoshita, T. Yamabi, Y. Enomoto, A. Hirata, T. Araki, Y. Nanishi and Y. Aoyagi, Appl .Phys. Lett. 80, 207 (2002).

[20] M. A. Moram, and M. E. Vickers, Rep. Prog. Phys. 72, 036502 (2009).

[21] J. R. Tesmer, M. Nastasi, Handbook of modern ion beam material analysis (MRS, Pittsburg, 1995).

[22] A. Redondo-Cubero, R. Gago, F. González-Posada, U. Kreissig, M.-A. di Forte Poisson, A.F. Braña and E. Muñoz, Thin Solid Films 516, 8447 (2008).

[23] L. C. Feldman, J. W. Mayer and S. T. Picraux, Materials analysis by ion channelling (Academic Press, New York 1982).

[24] E. Kótai, Nucl. Instrum. Meth. B 85, 588 (1994). 
[25] L. Vegard, Z. Phys. 5, 17 (1921). 


\section{FIGURE CAPTIONS:}

Figure 1. (Color on line) Kink angle $(\Delta \theta)$ detection along the $<\overline{2} 113>$ axis in an AlInN/GaN HS. The different positions of the minima in the angular scan are related with the lattice parameters and can be used to extract the strain state of the film.

Figure 2. (Color on line) Random and $<0001>$ aligned spectra (circle and squares) from $\mathrm{RBS} / \mathrm{C}$ experiments performed with $1.5 \mathrm{MeV} \mathrm{He}^{+}$ions. Composition and dechanneling of the layer was fitted by the simulation (solid line). Three selected energy windows for the channeling analysis are also exposed.

Figure 3. (Color on line) Compositional depth profile extracted from RBS simulation. Two different compositions are distinguished for the surface $(0-60 \mathrm{~nm})$ and the interface $(60-110 \mathrm{~nm})$ of the AlInN layer.

Figure 4. (Color on line) Experimental angular scans across $<0001>$ and $<\overline{2} 113>$ axes. The measured kink angle is $0.36^{\circ}$ corresponding to a relaxed $\mathrm{Al}_{0.82} \mathrm{In}_{0.18} \mathrm{~N}$ layer.

Figure 5. (Color on line) Reciprocal space maps for HR-XRD measurements along (0004) and (1015) planes. Pseudomorphic growth is confirmed with an almost null strain state of the film. The dashed lines in the (1015) map indicate the positions for fully strained and relaxed $\mathrm{Al}_{1-\mathrm{x}} \mathrm{In}_{\mathrm{x}} \mathrm{N}$ layers. 


$$
<\overline{2} 113>
$$

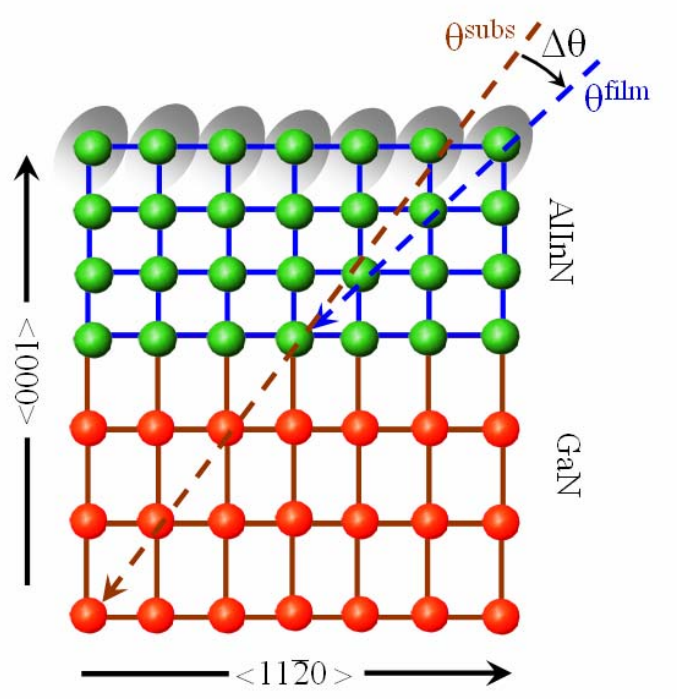

Figure 1 - A. Redondo-Cubero et al. 


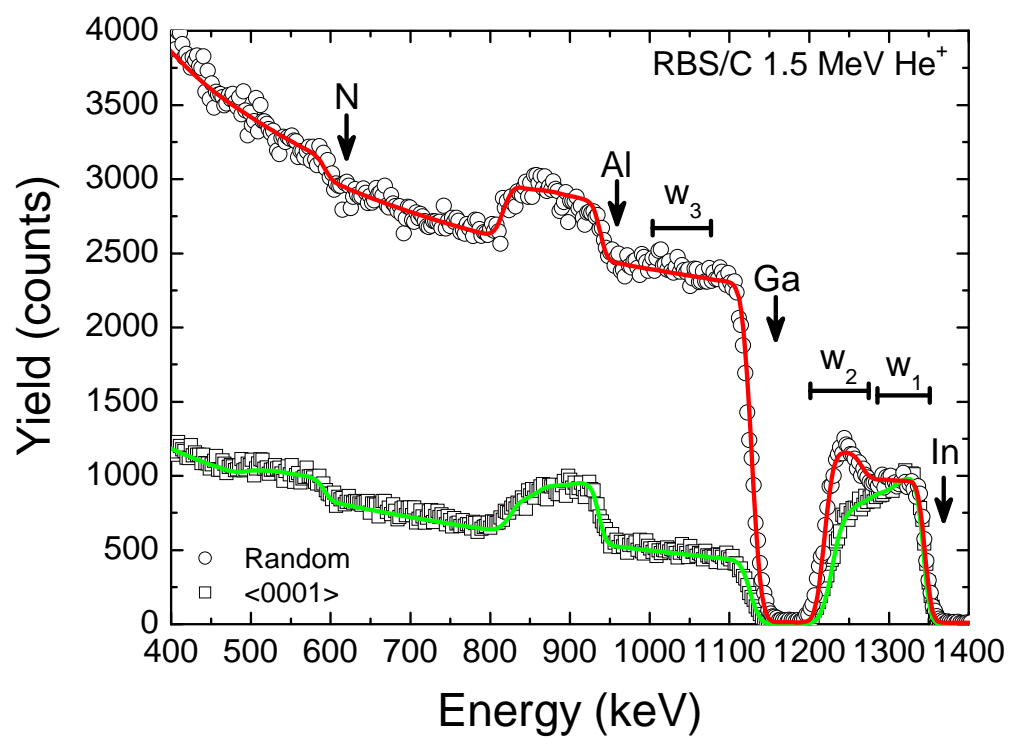

Figure 2 - A. Redondo-Cubero et al. 


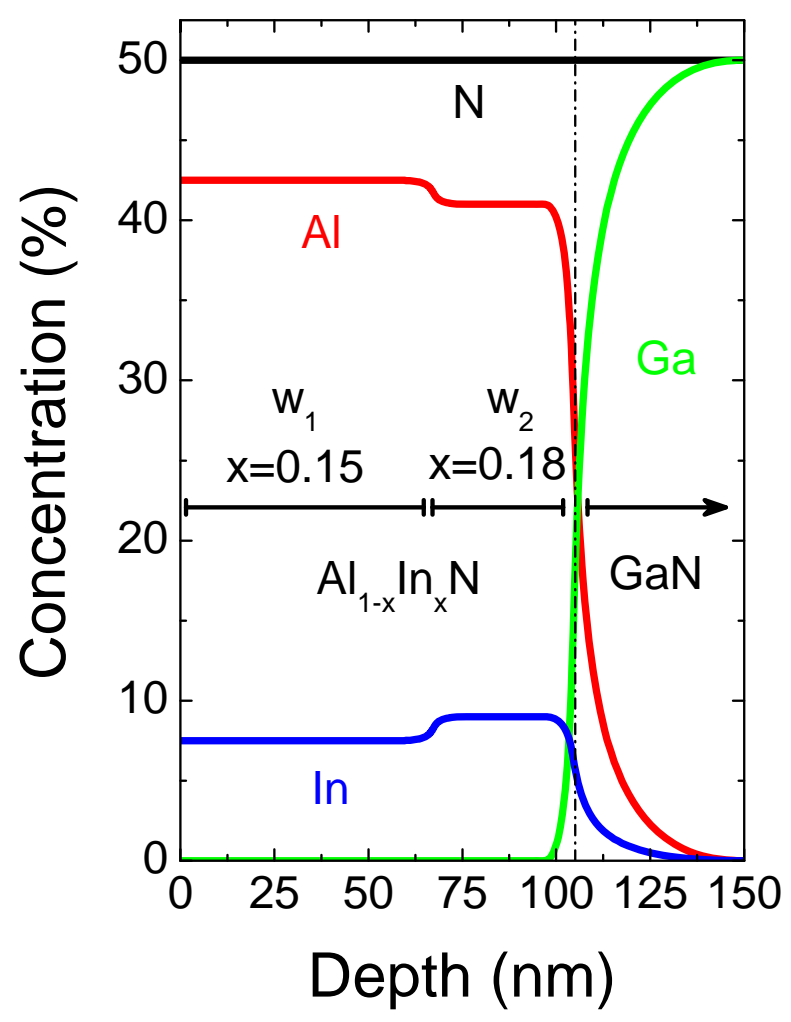

Figure 3 - A. Redondo-Cubero et al. 


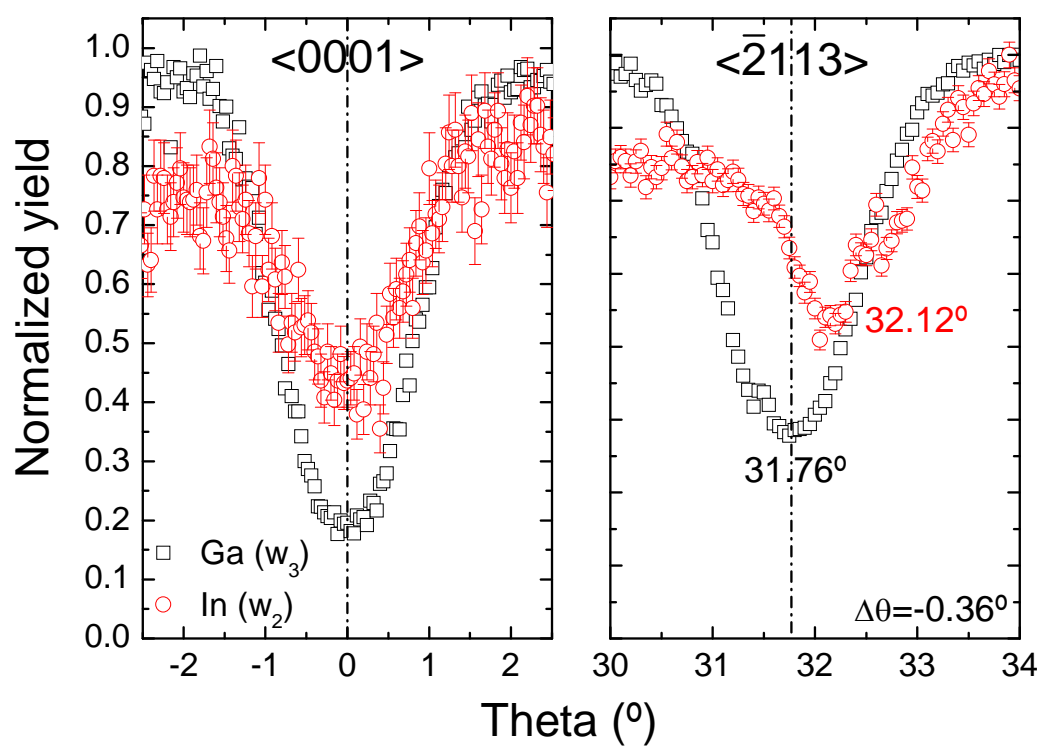

Figure $4-\mathrm{A}$. Redondo-Cubero et al. 


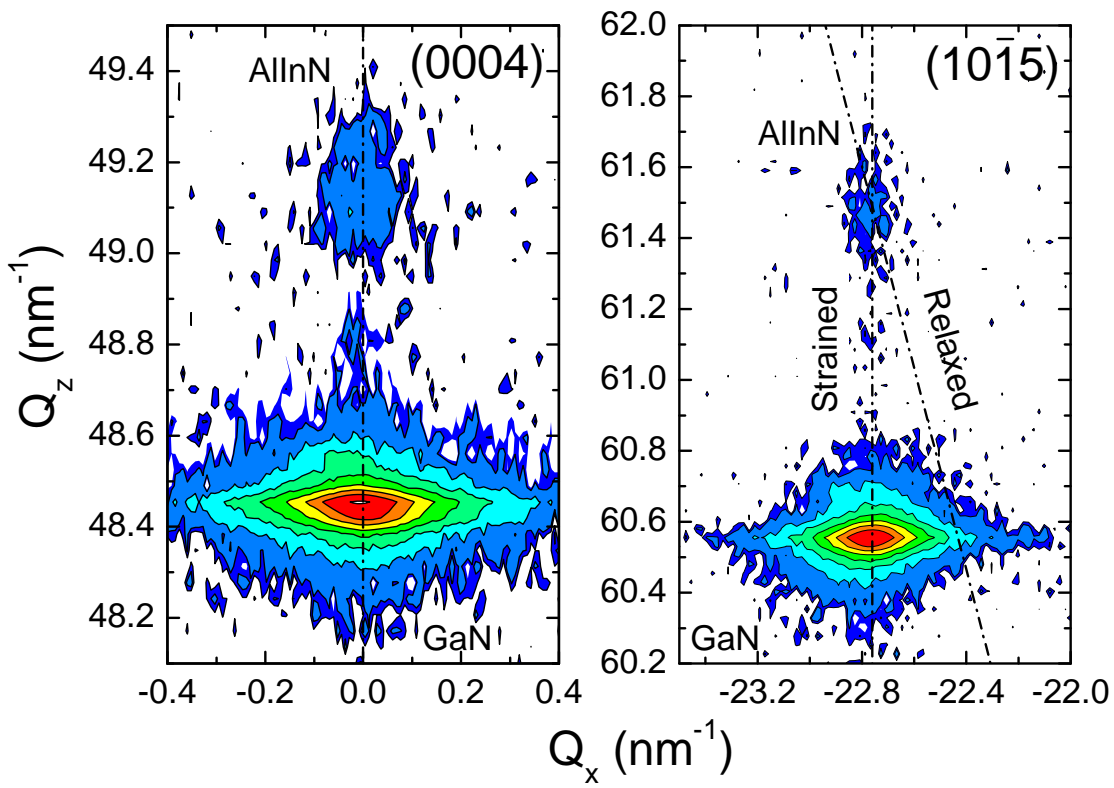

Figure 5 - A. Redondo-Cubero et al. 